\title{
Estrategias de Enseñanza para el Abordaje de Imágenes en Anatomía Patológica, Facultad de Odontología, Universidad Nacional de Córdoba, Argentina
}

\author{
Strategies of Education for the Study of Images in Pathology, \\ School of Dentistry, Universidad Nacional de Córdoba, Argentina
}

Gabriel Mario Fonseca \& Ana Carolina Fonseca

FONSECA, G. M. \& FONSECA, A. C. Estrategias de enseñanza para el abordaje de imágenes en Anatomía Patológica, Facultad de Odontología, Universidad Nacional de Córdoba, Argentina. Int. J. Morphol., 28(4):1113-1123, 2010.

RESUMEN: La enseñanza universitaria de las ciencias morfológicas suele presentar dificultades en la comprensión de sus imágenes, dada una aparente limitación de los estudiantes para la percepción eficiente de éstas. Estudios sobre las capacidades y especializaciones cognitivas asimétricas cerebrales, han evidenciado una actividad preponderante del hemisferio derecho en el procesamiento de las formas, colores y en el reconocimiento de sus patrones. Se analizaron las cohortes 1990 a 2004 (Grupo 1) y 2005 a 2009 (Grupo 2) de la asignatura Anatomía Patológica, Cátedra B, Facultad de Odontología de la Universidad Nacional de Córdoba, Argentina. En el Grupo 1 se implementó una metodología de exposición de imágenes en soporte póster y dibujo de las mismas, mientras que el Grupo 2 se aplicaron las técnicas de visualización de Edwards (bloqueo del hemisferio cerebral izquierdo y activación del derecho) modificadas para la exposición de imágenes en soporte guía impresa. Mientras que la estructura lógico-matemática de las preparaciones en el Grupo 1 indujo al estudiante a memorizar una determinada posición de la fotografía ó a desarrollar destrezas no competentes a los contenidos procedimentales de esta asignatura, las técnicas empleadas en el Grupo 2 permitieron potenciar la observación de formas, texturas y colores y las relaciones espaciales entre las estructuras, elementos inherentes a la exploración de imágenes en Anatomía Patológica. Se concluye que el abordaje de imágenes desde esta perspectiva neurobiológica y como estrategia de enseñanza, favorece y estimula el aprendizaje significativo en esta asignatura morfológica.

PALABRAS CLAVE: Enseñanza; Hemisferios cerebrales; Imagen; Patología.

\section{INTRODUCCIÓN}

El primer contacto del estudiante universitario con una disciplina morfológica es usualmente conflictivo, y la necesaria actitud visual exploratoria "aprendiendo a mirar" en función diagnóstica, es percibida como un violento "choque" (Nazer et al., 1977; Tamayo \& González, 2003). La frustración consecuente, deriva en una sensación de que las estrategias docentes resultan sosas y estructuradas, independientemente del nivel alcanzado. La imagen compone un elemento más a memorizar debido a una limitación en la plasticidad de su representación mental (Peresan \& Adúriz, 2010).

Investigadores del Instituto Tecnológico de California liderados por Roger W. Sperry, proporcionaron información sobre las diferentes maneras en que el cerebro procesa la información: el hemisferio cerebral izquierdo (HCI), lo hace de forma lineal, lógica y numérica alojando las funciones del lenguaje, mientras que el hemisferio cerebral derecho (HCD), es intuitivo, holístico, creativo, y conoce a partir de imágenes (Merlo, 2002). Esta asimetría supone diferentes modos de interpretar las percepciones y de procesar los datos: mientras que el HCD integra las imágenes y las formas, el HCI lee y nombra cada uno de los elementos con los que esas formas se construyen (Portillo, 2005) (Fig. 1).

Si bien las diferentes capacidades cognitivas evolucionan hacia la edad adulta, el progreso del abordaje imagenológico (expresado, por ejemplo, en el dibujo), parece detenerse a una edad temprana, resultando en inseguridades y frustraciones incluso en adultos competentes (Edwards, 1988). Según Llorente (2000), los estudiantes fra- 


\section{AMARILLO AZUL NARANJA NECRO ROJO VERDE MORADO AMARILLO ROJO NARANJA VERDE NEGRO AZUL ROJO MORADO VERDE AZUL NARANJA MARRON ROSA}

Fig. 1.Ejemplo visual del conflicto generado por la interacción de ambos hemisferios cerebrales: intente rápidamente decir el color de cada palabra sin leer lo escrito. Mientras el HCD intenta decir el color, el HCI (dominante y más rápido), insiste en leer la palabra.

casan al extraer la información relevante de las imágenes complejas porque no son capaces de usarlas apropiadamente. Sin embargo, se ha referido que no lograr ejecutar una determinada habilidad mental, no implica carecerla sino simplemente desconocer las destrezas implicadas en su ejecución (Edwards, 1988; Llorente).

Betty Edwards (1988, 2004), profesora de dibujo en la Universidad de California, desarrolló un método de enseñanza basado en sus investigaciones sobre la relación entre el dibujo, la percepción de los colores y los procesos de los hemisferios cerebrales. Apoyándose en la necesidad de bloquear al HCI (ya que es el derecho el encargado de dibujar una forma observada), diseñó una serie de simples ejercicios planteándole al cerebro una tarea que el HCI no pueda realizar (Tabla I). Afirmó que los adultos no ven lo que en realidad tienen ante los ojos y traducen lo percibido a palabras y símbolos, apoyándose en realidad en lo que saben del objeto percibido.

La enseñanza de las ciencias morfológicas suele presentar grados de dificultad en la comprensión de sus imágenes, debido a una inmadurez cognitiva en la resolución de los sistemas simbólicos. Interpretar imágenes es disponer de una habilidad que se aprende y perfecciona con la práctica de describir, identificar, comparar, clasificar, explicar, definir e interpretar estructuras visuales, y se ha propuesto analizarlas desde las artes plásticas para potenciar esta capacidad de interpretación (Peresan \& Adúriz).

Se analizaron las estrategias docentes de exposición y abordaje de las imágenes en la Cátedra B de la asignatura Anatomía Patológica, Facultad de Odontología de la Universidad Nacional de Córdoba, Argentina comparando una tradicionalmente expositiva con otra implementando técnicas de bloqueo del HCI y activación del HCD.

Tabla I. Ejercicios diseñados por Edwards (1988) para modificar la percepción visual a través del bloqueo del HCI y estimulación del HCD.

\begin{tabular}{|c|c|c|}
\hline Ejercicio & Técnica & Fundamento \\
\hline $\begin{array}{l}\text { Dibujo de copas-caras } \\
\text { (Simetría y espejo) }\end{array}$ & $\begin{array}{l}\text { Dibujar primero un perfil humano en el lado izquierdo } \\
\text { del papel, mirando hacia el c entro. Luego, un segundo } \\
\text { perfil como un doble invertido del primero (resultará una } \\
\text { copa simétrica). }\end{array}$ & $\begin{array}{l}\text { Perder la sensación de estar dibujando un perfil para } \\
\text { poder visualizar el espacio entre los dos perfiles, } \\
\text { apreciando ángulos, curvas, entrantes y s alientes, y } \\
\text { longitudes de línea, relacionando las formas opuestas. }\end{array}$ \\
\hline Dibujo invertido & $\begin{array}{l}\text { Tomar un dibujo o fotografía preferiblemente en blanco } \\
\text { y n egro e i ntentar copiar lo colocado todo en posición } \\
\text { invertida y si empre concentrado en lo que se ve. }\end{array}$ & $\begin{array}{l}\text { Cuando una imagen se ve in vertida las pistas visuales } \\
\text { no concuerdan, es casi imposible reconocer las } \\
\text { relaciones entre partes. Comienzan a visualizarse sólo } \\
\text { manchas y líneas, las partes de la imagen. }\end{array}$ \\
\hline Dibujo de contornos puros & $\begin{array}{l}\text { Dibujar la propia mano de manera que la que sujeta el } \\
\text { lápiz esté lista para dibujar sobre el p apel, y siempre } \\
\text { mirando la que tiene que copiar. No puede observarse lo } \\
\text { que se está dibujando. }\end{array}$ & $\begin{array}{l}\text { El mirar hacia otro lado es necesario por dos razones: } \\
\text { enfocar la atención en la información visual y no } \\
\text { dedicar ninguna atención al dibujo (puede contaminar } \\
\text { el dibu jo con viejos patrones simbólicos aprendidos }\end{array}$ \\
\hline $\begin{array}{l}\text { Dibujo de espacio vacío ó } \\
\text { negativo }\end{array}$ & $\begin{array}{l}\text { Hacer una composición de un objeto mediano ó pequeño. } \\
\text { Colocar detrás una cartulina de color fuerte (fondo) que } \\
\text { contraste con el objeto (figura). Dibujar solamente los } \\
\text { espacios de cartulina que no son tapados por el objeto, } \\
\text { tratando de ver las formas "negativas" y no las figuras. }\end{array}$ & $\begin{array}{l}\text { El hemisferio izquier do no puede tratar con el espacio } \\
\text { vacío. No puede nombrarlo, reconocerlo, hacerlo } \\
\text { coincidir con categorías memorizadas; carece de } \\
\text { símbolos preparados para ello. }\end{array}$ \\
\hline
\end{tabular}




\section{MATERIAL Y MÉTODO}

Se analizaron las estrategias docentes de exposición y abordaje de imágenes en la Cátedra B de la asignatura Anatomía Patológica (AP) de la Facultad de Odontología de la Universidad Nacional de Córdoba en las cohortes 1990 a 2004 y 2005 a 2009. Durante los seis meses al año que demandó cada cohorte, la enseñanza de AP se sustentó en clases magistrales teóricas no obligatorias (un promedio total de 96 horas, a razón de 4 hs semanales) y en el desarrollo de 19 actividades prácticas obligatorias (57 horas, a razón de 3 horas semanales). Estas actividades prácticas estuvieron a cargo del personal auxiliar docente con un promedio de 20 alumnos (relación 1/20) trabajando en cada una de las dos salas de trabajos prácticos con que cuenta la cátedra. Si bien la relaciones docente/alumno y horas/alumno fueron las mismas para estas actividades prácticas durante las cohortes informadas, las estrategias utilizadas para el abordaje de las imágenes fueron discriminadas en dos Grupos específicos:

\section{Grupo 1: Años 1990-2004 - Estrategia de enseñanza "póster"}

Se utilizaron 11 pósters en soporte madera con un promedio de 20 fotografías color de $15 \times 20 \mathrm{~cm}$ cada una. Las imágenes fueron seleccionadas por lo representativas del eje temático de cada póster e incluyeron fotografías clínicas, radiológicas, macroscópicas y microscópicas.

\section{Etapas y tiempos.}

- Primera: el auxiliar docente realizó la apertura vertiendo un resumen de la totalidad de los conceptos teóricos necesarios de cada actividad con un tiempo promedio de 60 minutos.

- Segunda: los estudiantes debieron dibujar cada una de las fotografías del póster correspondiente a ese trabajo práctico con una demanda de tiempo no inferior a los 90 minutos.

-Tercera: en un tiempo aproximado a los 30 minutos, el auxiliar docente se encargó de explicar cada una de las imágenes y dar las referencias morfológicas que fueron agregadas por los estudiantes en sus dibujos, siendo éstos finalmente su material gráfico de estudio.

-Cuarta: el cierre a cargo del auxiliar docente se realizó abarcando el tiempo restante del trabajo práctico y dependiendo del empleado en las etapas segunda y tercera.

-Evaluación: individual y oral, utilizando los mismos recursos gráficos. El auxiliar docente solicitó al estudiante la referencia a partir de una imagen en particular o, a la inversa, desde un diagnóstico especifico, el estudiante debió corresponderlo con una imagen.

\section{Grupo 2: Años 2005-2009 - Estrategia de enseñanza "guía"}

Se utilizaron guías en soporte papel A4, cada una de ellas correspondiente a una de las tres unidades temáticas sobre la que se construye el programa: Patología General, Patología Especial I y Patología Especial II. Las tres guías fueron concebidas sobre casos ficticios diseñados en base a los remitidos para estudio a la cátedra, y contaron con un promedio de 140 fotografías color cada una (clínicas, radiológicas, macroscópicas y microscópicas), respaldadas con sus homólogas en escala de grises y el protocolo correspondiente (ofreciendo los datos clínicos y quirúrgicos de cada caso, su diagnóstico presuntivo y la/s técnica/s empleadas en la confección del preparado) (Fig. 2). Todas las fotografías contaron con un tamaño promedio de $6 \times 4 \mathrm{~cm}$. El diseño gráfico se sustentó en las técnicas de desactivación del modo cerebral izquierdo y activación del modo cerebral derecho de procesamiento descriptas por Edwards (1988, 2004):

Emparejamiento imágenes color y en escala de grises: la apreciación de los atributos del color: matiz, luminosidad y saturación, suelen ser problema frecuente en la percepción. Los colores rosado y violeta de la $\mathrm{H} / \mathrm{E}$, siendo diferentes matices, prácticamente poseen la misma luminosidad en la escala de grises, mientras que la saturación, en este caso el grado de apetencia tintorial, puede ser perfectamente diferenciable en las imágenes en grises (Fig. 3). Los cotejos de ambas imágenes permiten potenciar estas diferentes percepciones aplicándolas a la valoración de las tinciones.

Planteo aleatorio de imágenes en espejo ó invertidas: el HCI, rechaza el procesar imágenes espejadas o invertidas dejando al HCD el ocuparse de las formas, sombras y colores (Fig. 4).

Planteo aleatorio de imágenes símiles no iguales: los símbolos de procesamiento del HCI no concuerdan; el HCD se libera para procesar y fijar mentalmente las relaciones y los patrones de semejanza entre sí (Fig. 5).

\section{Etapas y tiempos.}

-Primera: con un tiempo máximo de 15 minutos, el auxiliar docente realizó la apertura dando sucintamente los contenidos conceptuales necesarios para el abordaje de los diferentes casos.

-Segunda: los estudiantes fueron divididos en un máximo de 6 grupos de 3 individuos cada uno para realizar los 

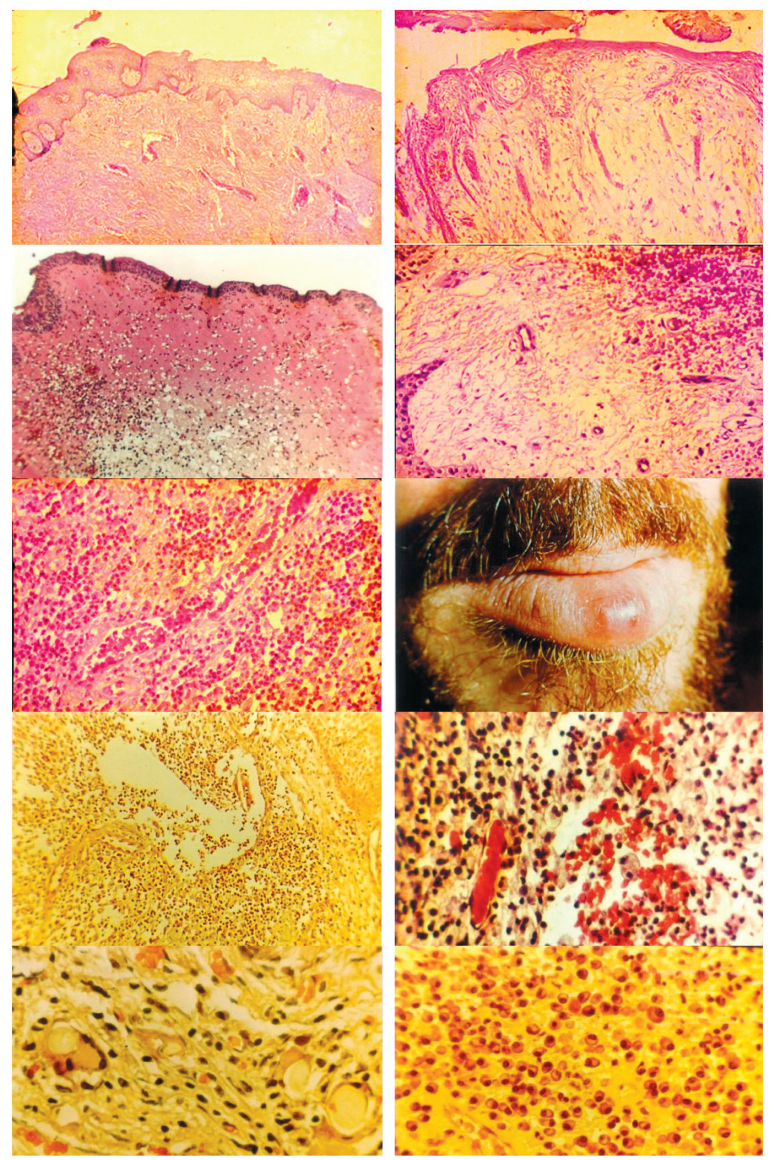
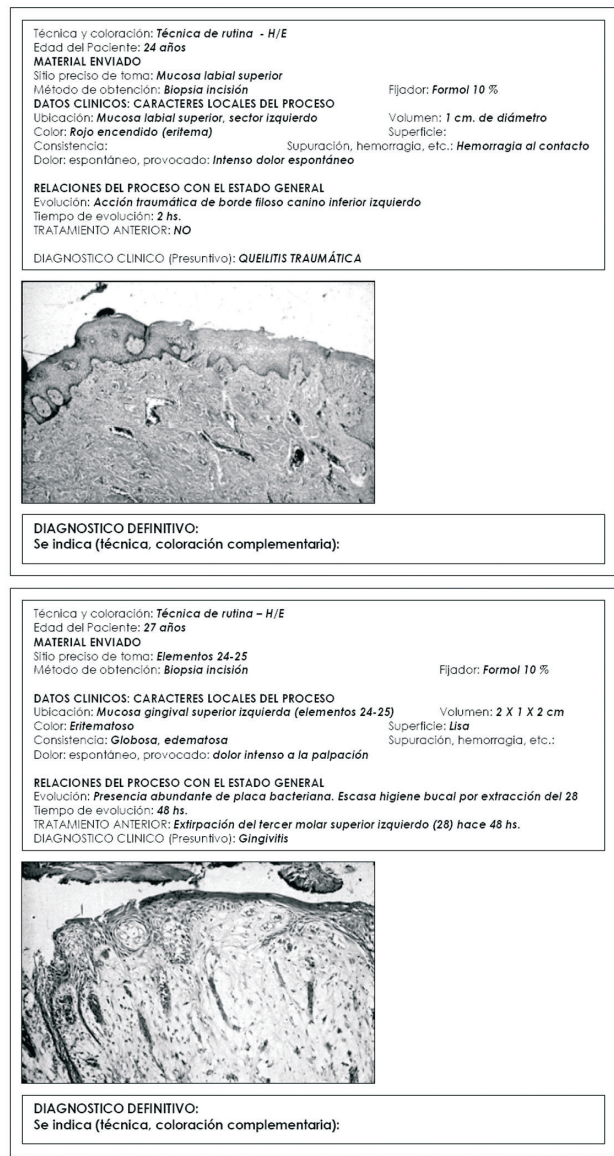

Fig. 2. Estrategia de enseñanza "guía", soporte papel. Izq.: Imágenes color; Der: Homólogas en escala de grises junto a los protocolos clínico-quirúrgicos correspondientes. Los casos fueron ficticios, pero diseñados sobre remitidos para estudio a la cátedra.
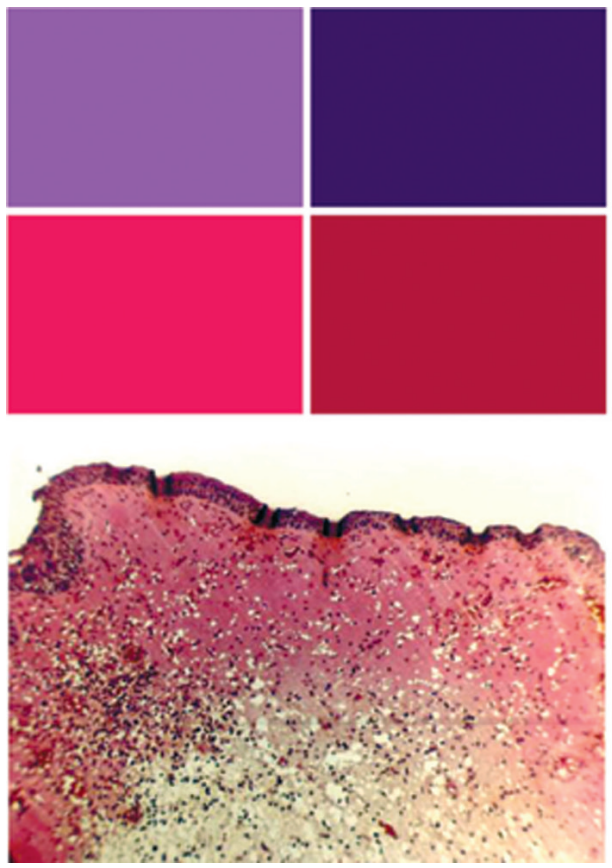
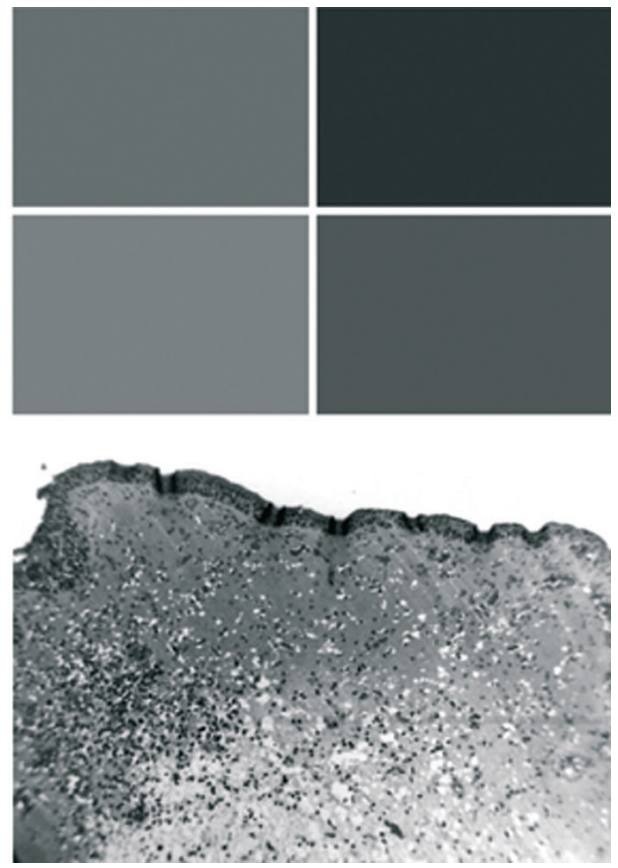

Fig. 3. Estrategia de enseñanza "guía". Emparejamiento imágenes color y en escala de grises. Arr.: los colores rosado (eosina) y violeta (hematoxilina), aun componiendo diferentes matices, prácticamente poseen la misma luminosidad en la escala de grises. Así mismo, esta escala permite diferenciar grados de saturación. Ab.: el exudado fibrinoso (enmascaramiento rosado en la preparación en colores), puede apreciarse como un aumento de la intensidad, evidente en la preparación en grises. Esto permite al estudiante valorar y completar el concepto de intensidad en la apetencia tintorial. 


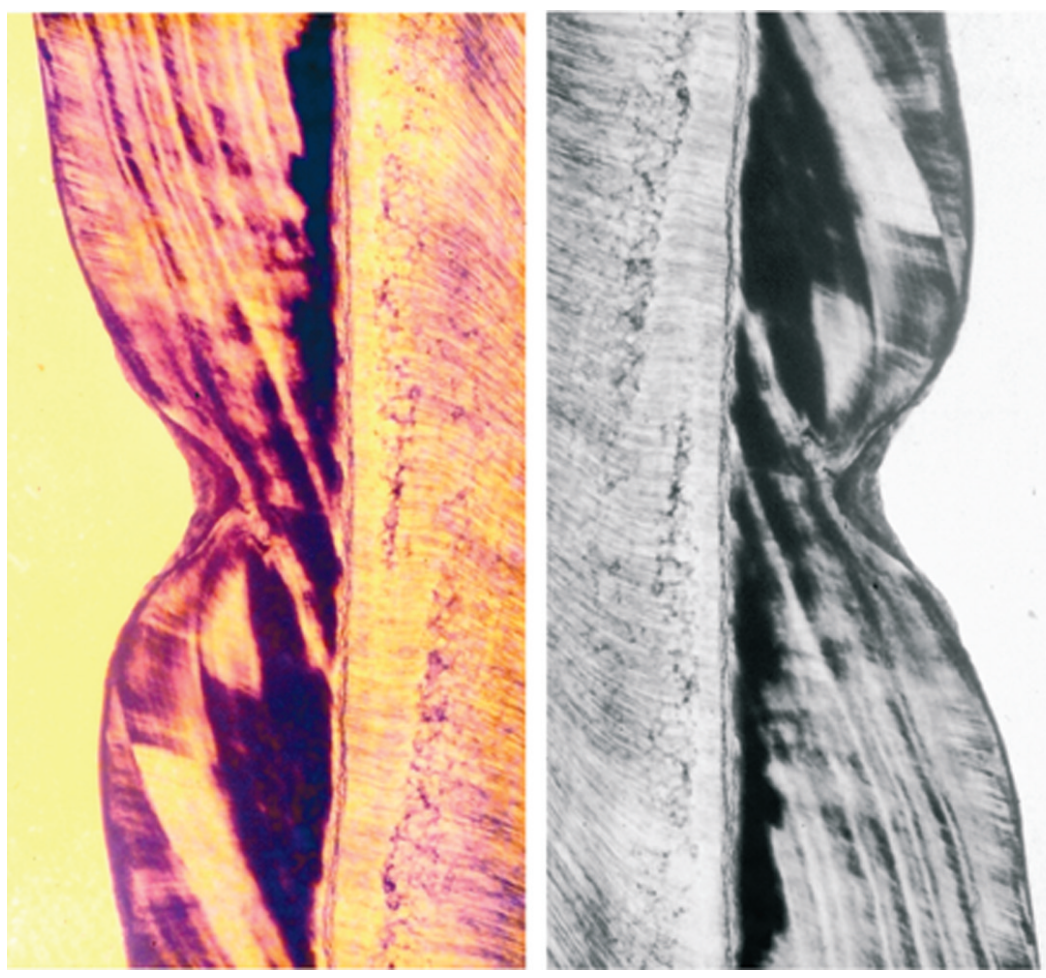

Fig. 4. Estrategia de enseñanza "guía". Planteo aleatorio de imágenes en espejo ó invertidas. Si bien no molesta ver las imágenes alteradas en su posición, el relacionar ambas imágenes obliga a dejar de lado símbolos propios de HCI para dar lugar a la pura observación de formas. En las imágenes (hipoplasias adamantinas), la comparación permite visualizar el eje diagnóstico (la estría adamantina gigante) dejando de lado los preconceptos de oclusal arriba (en la imagen en colores), fosa oclusal lateralizada (error común en la percepción de nuestros estudiantes), etc.
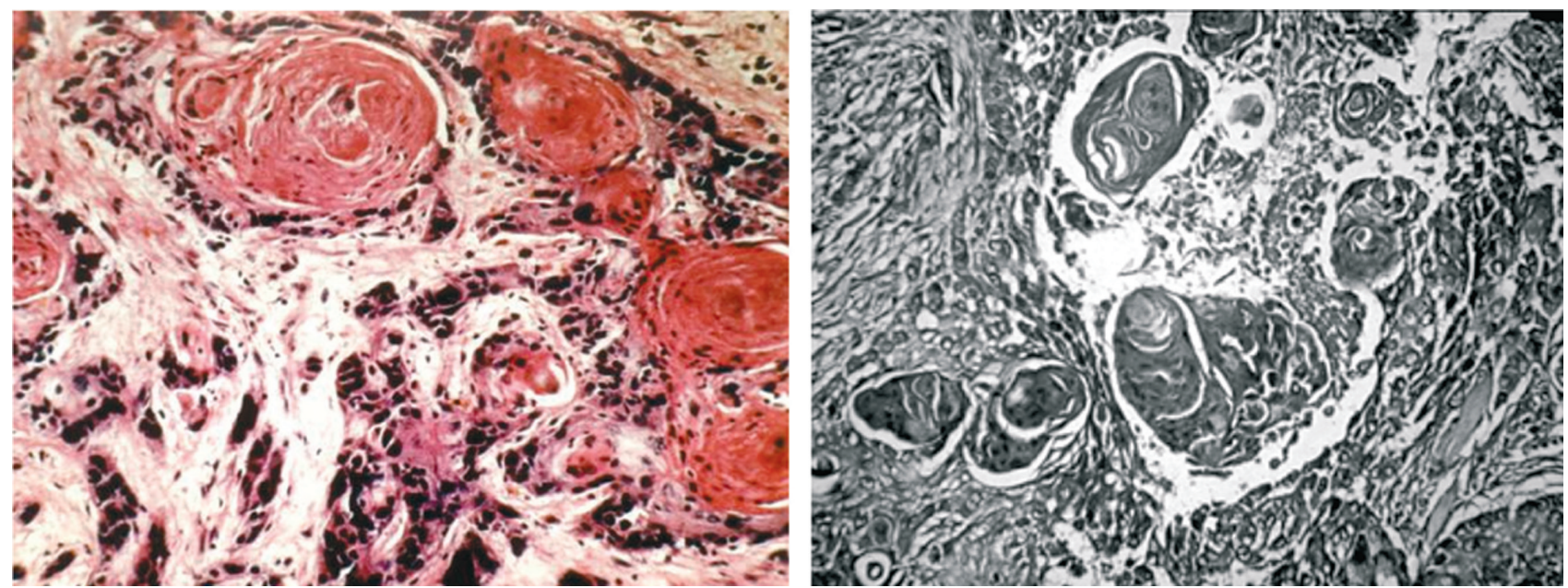

Fig. 5. Estrategia de enseñanza "guía". Planteo aleatorio de imágenes símiles no iguales. Permite la fijación de los patrones morfológicos semejantes. En la imagen, las perlas de queratina (disqueratosis) y los islotes de epitelio displásico propios de un carcinoma epidermoide diferenciado.

diagnósticos definitivos y confeccionar los informes sobre dos casos específicos. Se estableció como consigna que cada estudiante efectuara una lectura de los protocolos involucrados y luego, durante un mínimo de 10 minutos y en silencio, observe atenta y simultáneamente las imágenes color y en escala de grises para favorecer el modo de procesar la información visual. El auxiliar docente ofició de guía en esta instancia ayudando a "mirar lo que se debe mirar", cuidando de no dar nombres o significación simbólica a las imágenes. Luego se abordaron grupalmente los diagnósticos, avalando o no los presuntivos de cada protocolo. Según el caso, debieron solicitar procedimientos complementarios (ej.: Técnica de PAS) ó realizar sugerencias al clínico (ej.: controles periódicos del paciente por potenciales recidivas) emulando la tarea del patólogo. El tiempo para la tarea diagnóstica grupal fue de aproximadamente unos 60 minutos. 
-Tercera: cada grupo realizó la presentación oral de sus casos justificando con hallazgos morfológicos los diagnósticos realizados. Mientras que el auxiliar docente ofició de guía u orientador, los grupos restantes debían ejercer como evaluadores corrigiendo o complementando al grupo expositor. El tiempo de esta actividad fue de un promedio de 60 minutos.

-Cuarta: el cierre a cargo del auxiliar docente se realizó abarcando el tiempo restante del trabajo práctico y dependiendo del empleado en las etapas segunda y tercera.

-Evaluación: individual y escrita. Se utilizaron las imágenes en escala de grises impresas con los correspondientes protocolos y conjuntamente con la proyección multimedia de la imagen color siguiendo las mismas técnicas descriptas arriba. Los estudiantes debieron confeccionar sus informes colocando las referencias en la fotografía que justificaran el diagnóstico realizado. Al igual que en las actividades prácticas y según el caso, debieron solicitar procedimientos complementarios ó realizar sugerencias al clínico. Se utilizaron las mismas fotografías y protocolos empleados en las guías.
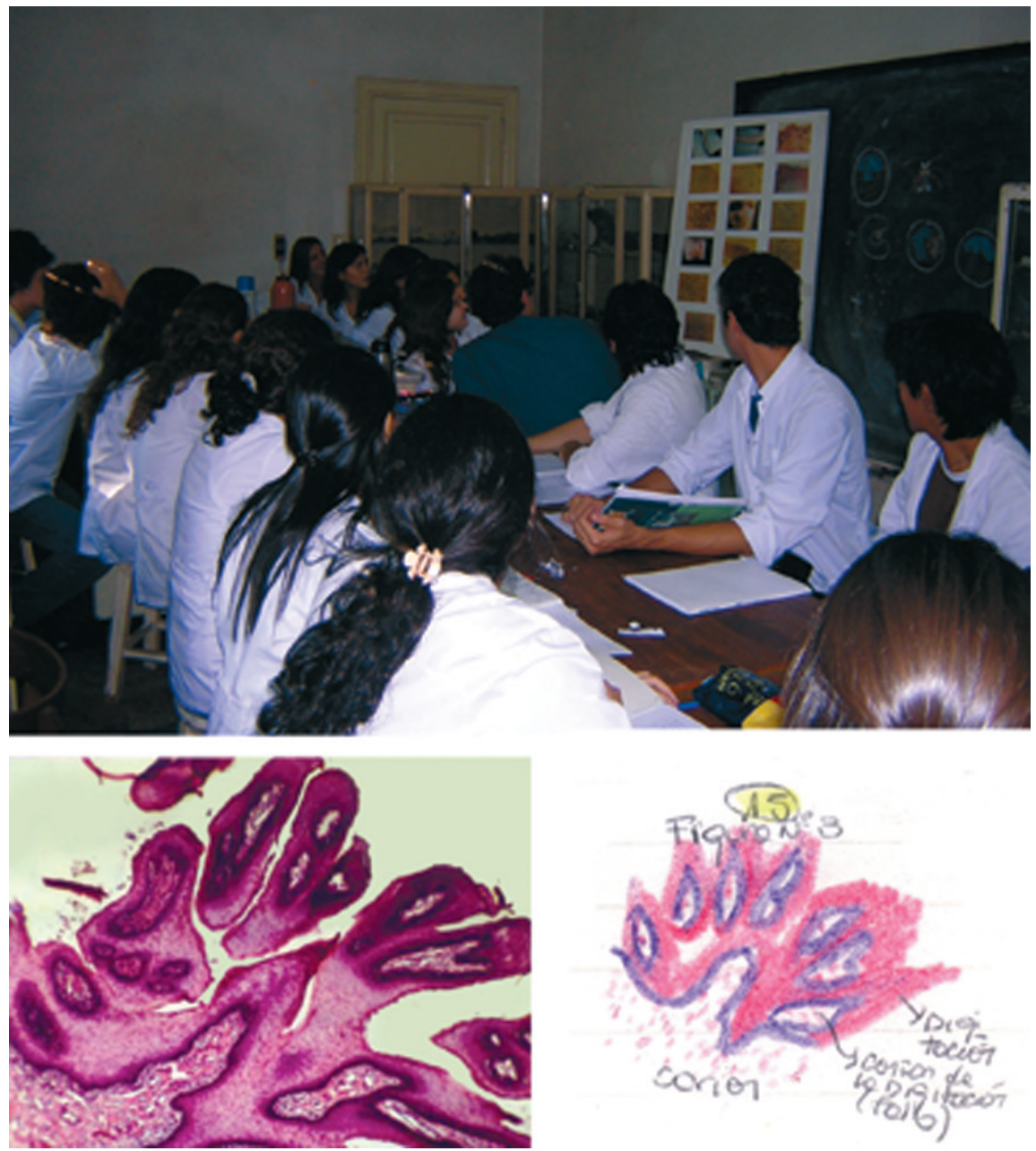

Fig. 6. Estrategia de enseñanza "póster". Arr.: Inadecuados tamaños de las fotografías para la distancia y ubicación espacial de los individuos en el Grupo 1. La estructura lógico-matemática de las fotografías en el póster favoreció el aprendizaje memorístico. Ab.: preparación histológica (Izq.) y copia realizada por el estudiante (Der.); obsérvese el resultado poco satisfactorio y la excesiva importancia dada al número de imagen y posición en el póster. 
Tabla II. Comparación entre el Grupo 1 (estrategia «poster» y el grupo 2 («estrategia guía»).

\begin{tabular}{|c|c|c|}
\hline Item & Grupo 1 & Grupo 2 \\
\hline $\begin{array}{l}\text { Confección y logística de } \\
\text { utilización }\end{array}$ & $\begin{array}{l}\text { La estrategia de pósters permitió un } \\
\text { manejo rápido, sencillo y económico de } \\
\text { la información gráfica. Una vez } \\
\text { confeccionados, pudieron reutilizarse } \\
\text { tantas veces fue necesario. }\end{array}$ & $\begin{array}{l}\text { Guías con diseño y c onfección complejos. Cada } \\
\text { año debieron reimprimirse con costos a cargo del } \\
\text { estudiante. }\end{array}$ \\
\hline $\begin{array}{l}\text { Distribución de tiempos/etapas } \\
\text { en la estrat egia docente }\end{array}$ & $\begin{array}{l}\text { Excesivo tiempo dedicado a la repetición } \\
\text { de conceptos ya dados en clases } \\
\text { magistrales y a la confección de los } \\
\text { dibujos (Primera y Segunda Etapas). } \\
\text { Referenciado acelerado con nula } \\
\text { participación de los estudiantes y escaso } \\
\text { tiempo para la resolución de dudas } \\
\text { (Tercera Etapa). Ausencia frecuente de } \\
\text { cierre por las mismas razones (Cuarta } \\
\text { Etapa). }\end{array}$ & $\begin{array}{l}\text { Distribución más eficiente sin redundancia de } \\
\text { conceptos (Primera etapa), potenciando los } \\
\text { momentos específicamente dedicados a la } \\
\text { exploración visual en función diagnóstica } \\
\text { (Segunda y Tercera etapas). Mayor y mejor } \\
\text { tiempo para el cierre y l a evacuación de dudas } \\
\text { (Cuarta etapa). }\end{array}$ \\
\hline $\begin{array}{l}\text { Formato y abordaje visual de } \\
\text { las imágenes }\end{array}$ & $\begin{array}{l}\text { Tamaño y distancia inadecuados para la } \\
\text { observación; los estudiantes debieron } \\
\text { reacomodar constantemente sus } \\
\text { posiciones en la sala para poder } \\
\text { percibirlas de forma adecuada. La } \\
\text { estructura lógico-matemática de las } \\
\text { fotografías en el s oporte originó una } \\
\text { perjudicial comodidad para la } \\
\text { percepción memorística del HCI. }\end{array}$ & $\begin{array}{l}\text { Cada estudiante accedió a su propio material de } \\
\text { estudio en un formato archivable y d e fácil } \\
\text { observación. El bloqueo del HCI y activación del } \\
\text { HCD con la conducción del auxiliar docente, } \\
\text { potenciaron la observación adecuada de formas, } \\
\text { texturas, colores y l as relaciones espaciales entre } \\
\text { las estructuras. }\end{array}$ \\
\hline Contenidos Conceptuales & $\begin{array}{l}\text { Reiterativos y desinsertados de la } \\
\text { exploración visual de las preparaciones. }\end{array}$ & $\begin{array}{l}\text { No se reiteraron en el desarrollo de las actividades } \\
\text { prácticas ya que las clases magistrales constituían } \\
\text { la instancia previa y necesaria para afrontarlas. El } \\
\text { auxiliar docente, en su papel de conductor o guía, } \\
\text { sólo subrayó aquellos contenidos necesarios e } \\
\text { inherentes al diagnóstico. }\end{array}$ \\
\hline Contenidos Procedimentales & $\begin{array}{l}\text { Los dibujos, contenido alejado } \\
\text { drásticamente del objetivo de la AP: la } \\
\text { observación en función diagnóstica. } \\
\text { Resultados insatisfactorios inútiles para } \\
\text { un posterior estudio y repaso. }\end{array}$ & $\begin{array}{l}\text { Más cercanos a los de la AP al permitir abordar las } \\
\text { imágenes apoyándose en un protocolo clínico- } \\
\text { quirúrgico centralizando todo en la exploración. } \\
\text { Inserción del estudiante en la s ecuencia salud- } \\
\text { enfermedad acercándolo a la rutina de trabajo del } \\
\text { patólogo. }\end{array}$ \\
\hline Contenidos Actitudinales & $\begin{array}{l}\text { La presentación aislada de las imágenes } \\
\text { llevó al estudiante a una alienación y } \\
\text { ausencia en su vinculación empática, } \\
\text { observando solamente un preparado y no } \\
\text { un eslabón de la cadena diagnóstica. }\end{array}$ & $\begin{array}{l}\text { E1 uso del protocolo permitió establecer la } \\
\text { contextualización clínica, quirúrgica y terapéutica } \\
\text { del preparado como representación visual de un } \\
\text { paciente enfermo. La confección del informe } \\
\text { anatomopatológico obligó al es tudiante a to mar } \\
\text { participación determinante en una certeza } \\
\text { diagnóstica donde el tratamiento dependerá de lo } \\
\text { que el patólogo informe. }\end{array}$ \\
\hline
\end{tabular}

Los dibujos no ofrecieron beneficio alguno como estrategia en el Grupo 1: a la vez que demandaron excesivo tiempo en sus confecciones, provocaron una constante sensación de frustración en gran parte de los estudiantes al no obtener resultados satisfactorios (Fig 6). Esto los inutilizó como elemento posterior de estudio.

La confección del informe en el Grupo 2, acercó a los estudiantes a los necesarios contenidos actitudinales y empáticos propios de la labor en AP. El tener que corroborar los diagnósticos presuntivos del protocolo y con esto, justificar un posterior tratamiento (en algunos casos tremendamente invasivo), posicionó a los estudiantes en la concientización de que el preparado nace de un procedimiento quirúrgico (cruento) donde el paciente conlleva una historia previa y depende en gran medida de su diagnóstico (¿cáncer?) para un nuevo procedimiento terapéutico. De manera alarmante, pudo observarse en el Grupo 1 que el estudiante no logró vincular las imágenes con el sentido clínico de éstas. 


\section{DISCUSIÓN}

El estudiante de AP, asignatura del segundo año de la carrera de Odontología de la Universidad Nacional de Córdoba, se ve obligado en el corto periodo de seis meses y sin contacto alguno con la clínica, a adquirir el "raro don divino" de la exploración morfológica en función diagnóstica, contando solo con las destrezas adquiridas (y mínimamente desarrolladas) en las previas Histología y Anatomía.

Dionisio de Cabalier \& Chalub (2009) expusieron su experiencia en la enseñanza de la disciplina Clínica Dermatológica, siguiendo el modelo cognitivo de relacionar conocimientos teóricos y prácticos: para que cada concepto pueda ser aprendido significativamente, el estudiante debe ser capaz de entender su significado. Según esta perspectiva, la comprensión de un término médico teórico va a sustentarse en el reconocimiento de los indicios clínicos, macroscópicos o microscópicos del paciente. Esta proposición se fundamenta en una enseñanza de menor a mayor complejidad, incluyendo de manera paulatina los conceptos de: células, tejidos, anatomía y patologías de los mismos.

Sin embargo, y desde una mirada opuesta, Tamayo \& González encuentran que es la necesidad de conceptualizar la que origina los mayores problemas en la enseñanza morfológica: el concepto de "tejido" resulta difícil de definir, las ciencias entregan conocimientos provisorios y de constante revisión y la inercia en la enseñanza básica o media conserva conceptos y clasificaciones antiguos incorporando a la vez nuevos conocimientos en forma contradictoria o ilógica. Llorente coincide al considerar que se obtienen mejores resultados con las imágenes que con las palabras.

Se han formulado propuestas de enseñanza con apoyo en TICs -nuevas tecnologías de información y comunicación- (Ávila et al., 2002; Rodríguez et al., 2005). García (2006) afirma que el aprendizaje de una ciencia morfológica, debe apoyarse en la mayor cantidad de variables, con aplicación permanente de estas TICs, para favorecer la utilización de todos los tipos de inteligencia de cada estudiante, según Gardner (2001). La misma AP ha sido foco de formulación de propuestas sustentadas en estas múltiples capacidades (García et al., 2009). Sin embargo, sólo presentar una imagen no es enseñar a interpretarla, ni siquiera utilizando estas tecnologías. Una encuesta realizada por Bruno et al. (2006) a estudiantes de Patología Oral y Clínica y Estomatológica de la Facultad de Odontología de la Universidad Nacional de La Plata, concluyó que los docentes deberían autoevaluar el proceso de enseñanza-aprendizaje, pues el estudiante parece responder mejor a los métodos expositivos tradicionales que a la promovida observación de imágenes multimedia, según estos autores, sólo "distractora". Puede hallarse explicación a esto en Pellón et al. (2009), quienes sugieren la presencia de incoherencias en el actuar pedagógico, hecho reflejado en estrategias centradas en el profesor y no en el estudiante como constructor de su propio aprendizaje.

Se ha coincidido en que una ciencia morfológica debe abordar a las imágenes mediante destrezas de naturaleza espacial para construir el conocimiento (Levie \& Lentz, 1982; Peresan \& Adúriz). Esta composición de la imagen como recurso educativo, desgraciadamente no encuentra sostén en la educación tradicional: mientras aumenta la densidad de imágenes y experiencias basadas en sistemas no verbales, la enseñanza sigue empecinándose en una alfabetización verbal de números y palabras. La consecuencia más trágica de esto puede apreciarse en una deshabituación de los estudiantes a considerar a las imágenes como una fuente seria de información (Edwards, 1988; Froufe \& Colom, 1999; Llorente). Levie \& Lentz pidiendo a un grupo de alumnos la lectura de un libro de textos ilustrado, descubrieron que algunos sujetos no habían siquiera mirado las imágenes y sólo el 25\% lo había hecho para divertirse mientras reía, ignorando los detalles y atendiendo solo los rasgos mencionados en el texto escrito.

Suazo et al. (2010) definen a los estilos de aprendizaje como los indicadores de la manera en que el alumno se aproxima al contenido para lograr el aprendizaje, lo que fundamenta el establecer la calidad de los contenidos a abordar. Nuevamente Pellón et al. (2009), apoyándose en el concepto de transposición didáctica como "el trabajo de transformación del objeto de saber en un objeto de enseñanza", aluden a la necesidad de adecuación de estos contenidos, el denominado Conocimiento Didáctico del Contenido (CDC). Nuestra experiencia en el Grupo 1 coincidió en su totalidad con las dificultades descritas por Pellón et al. (2009): las debilidades del desempeño docente, del medio (secuenciación y temporalización inadecuadas) y de la gestión directiva (ausencia de espacios formales de diálogo). Las necesidades implícitas de la AP fueron absolutamente obviadas por una enseñanza tradicional de los contenidos (oralidad preponderante, unidireccionalidad, ausencia de mediación pedagógica del docente como elemento orientador de autoaprendizaje). La presentación de imágenes estáticas y planteadas con un ordenamiento específico (pósters) permitió al lógico HCI trabajar agrupándolas, clasificándolas, dándoles nombre, exagerando un apoyo en lo conceptual y esquivando abiertamente el objetivo primordial de esta 
disciplina que es el observar y no solamente ver. De igual modo, también coincidimos con Levie \& Lentz en que el dibujar no solo no aportó mayor utilidad, sino que originó una dependencia de la capacidad de dibujo del propio estudiante (existe una clara tendencia a la realización de dibujos pobremente relacionados con los contenidos), destreza obviamente no competente a los contenidos de esta disciplina.

Profundizando aún más en la problemática: mientras que en su rutina el patólogo toma contacto con un material ya montado junto un protocolo donde constan datos orientativos (color de la lesión, consistencia, edad y situación médica previa del paciente, etc.), en el Grupo 1 el estudiante fue instado a diagnosticar con el solo amparo de la preparación microscópica, aun a sabiendas de que ni el más eficiente profesional puede hacerlo apoyado solo en esta imagen. Esta estrategia, evidentemente atentó contra la fundamental necesidad de transferencia del saber conceptual a un saber aplicado, sabiduría obtenida de la práctica misma (Pellón et al., 2010). Si bien el estudiante de $2^{\circ}$ año no ha realizado abordaje clínico alguno, la estrategia del Grupo 2 de presentar los casos acompañados con su protocolo clínico-quirúrgico, influyó muy positivamente en su experiencia diagnóstica: resultados preliminares sobre las cohortes 2002 a 2006 involucradas en este estudio (Fonseca \& Fonseca, 2008), pusieron en evidencia una franca disminución en la cantidad de alumnos valorados como "regulares" ó con dificultades para alcanzar los estándares mínimos en sus capacidades diagnósticas a través de las imágenes (promedio final <7.00): 32,97\% en $2002(n=367) ; 27,45 \%$ en 2003 $(n=306) ; 24,77 \%$ en $2004(n=327) ; 11,15 \%$ en $2005(n=278)$ y $8,64 \%$ en $2006(n=243)$.

Mayores logros pudieron percibirse también en el Grupo 2 en lo relativo al desarrollo empático; el alumno dejó de ver sólo "un preparado" para insertarse emotivamente en la necesaria secuencia del procedimiento diagnóstico. Pudo reconocer las existencia de una historia y una resolución muy dependiente de lo que él mismo vaya a informar (ej.: lesión en lengua-diagnóstico presuntivo de úlcera traumática crónica-diagnóstico histopatológico de cáncerderivación a oncología-cirugía invasiva, etc. El estudiante se vio comprometido en el proceso con un claro abarcamiento de los necesarios contenidos actitudinales. Las formas tradicionales de enseñanza de la AP se han fundado sólo en métodos explicativos imperando un paradigma biológico en el tratamiento de los contenidos, dejando de lado la visión integral del ser humano (nuevo paradigma social) (García \& Rego,1998). Se ha afirmado que sintonizar con las señales sociales sutiles y con la sensibilidad para captar los estados emocionales de los demás - la empatía- ayudan significativamente a la comunicación y al buen desempeño profesional, al altruismo y la ética (Froufe \& Colom).
"Una de las tareas que el patólogo realiza rutinariamente en el proceso del diagnóstico es la evaluación de la complejidad de la forma y textura de las imágenes microscópicas" afirman Val y Garijo (2003), y agregan: “(el patólogo) siguiendo un proceso de decisión, elabora un juicio que se traduce en una respuesta en el lenguaje patológico que incluye el diagnóstico y la designación de una conducta biológica". Entre las disciplinas odontológicas basando sus métodos de enseñanza en el manejo de contenidos visuales, la AP ha fundamentado este manejo de la imagen como contenido procedimental básico en el diagnóstico. Durante años se ha servido de representaciones simbólicas visuales para establecer patrones morfológicos macroscópicos, radiológicos e histológicos con expresiones curiosas tales como "en cielo estrellado", "en raqueta de tenis", "en baldosas flojas", "diente embarazado", "en ojos de lechuza", entre otras. Coincidiendo con Edwards (1988, 2004), nuestra experiencia nos ha revelado que la percepción de formas y colores de las imágenes, no puede sustentarse sólo en estas representaciones simbólicas pues sugieren fuertes patrones del HCI que dificultan la visión de cómo se ven en realidad (al día de hoy, pocos de nuestros estudiantes han logrado ver los "ojos de lechuza" en la célula de ReedSternberg). La premisa básica de las técnicas y estrategias formuladas en el Grupo 2 fue estimular a un pensamiento no hablado, brindar una visión nueva y más objetiva de las relaciones entre las partes, sin necesidad de explicar nada lógicamente porque toda la información necesaria visual está delante de los ojos. Edwards (1988) refiere que las más recientes investigaciones han indicado que el HCD, además de ser capaz de percibir formas, se encuentra especializado en el procedimiento de establecer patrones con ellas y a la vez, fijarlas para un ulterior reconocimiento. Imaginemos, o mejor, "reconozcamos" a esta capacidad como la de mayor basamento para un diagnóstico anatomopatológico.

Aunque cada hemisferio es dominante en ciertas actividades, los dos están básicamente capacitados en todas las áreas y, de hecho, las habilidades mentales identificadas por Roger Sperry se hayan distribuidas en toda la corteza cerebral. Nuevamente Edwards (1988) nos señala cuáles deberían ser las tareas pertinentes al docente: favorecer no solo al entrenamiento del hemisferio verbal y simbólico -el HCI- (ya sobreestimado en la educación tradicional), sino también al hemisferio espacial, holístico y relacionador -el HCD-, mayormente descuidado; preparar al estudiante para utilizar el estilo de cognición adecuado a la tarea que tenga entre manos y estimularle para la aplicación de ambos estilos de percepción con el objeto de abordar el problema de manera integrada. Mientras que en el Grupo 1, las clases mayormente oralizadas y la exposición estática de las imágenes fijaron a los estudiantes en el HCI, cuando se consiguió en el Grupo 2 que los estudiantes pasaran al modo 
cognitivo HCD, pudo conseguirse una condición muy rara en las aulas modernas: el silencio. Los estudiantes dejaron de hablar entre ellos y se encontraron enfrascados de forma confiada, atenta y bien dispuesta a la tarea encomendada. Resulta indispensable en estas condiciones, que el mismo docente favorezca y mantenga él mismo este silencio.

La fotografía como material didáctico, de alguna manera continúa alejándose de la realidad por representar solo una porción del espectro gráfico y por evadir otro con- tenido procedimental básico en AP: la utilización del microscopio y el recorrido del preparado buscando signos morfológicos diagnósticos. Así mismo, el permanente aumento en la cantidad de estudiantes, la provisión inadecuada de recursos y del mismo material de observación dada su alta susceptibilidad a extravíos o rupturas (todos elementos desgraciadamente inherentes a una universidad estatal) hacen necesaria una continua búsqueda de nuevas metodologías que permitan potenciar el ansiado "aprendizaje significativo".

FONSECA, G. M. \& FONSECA, A. C. Strategies of education for the boarding image in Pathology, School of Dentistry, Universidad Nacional de Córdoba, Argentina. Int. J. Morphol., 28(4):1113-1123, 2010.

SUMMARY: University education of the morphological sciences presents difficulties in the comprehension of its images because of an apparent limitation of the students to efficiently perceive these images. Studies on the capacities and cognitive asymmetric cerebral specializations, have demonstrated a preponderant activity of the right hemisphere in the processing of forms, colors, and in the recognition of their patterns. The 1990-2009 (Group 1) and 2005-2009 (Group 2) cohorts and B Department of Pathology of the School of Dentistry, National University of Cordoba, Argentina were studied. In Group 1 a methodology was implemented including exhibition and drawing of images in support poster and drawing of the same, whereas in Group 2 the modified Edwards techniques of visualization were applied, (blocking of the cerebral left hemisphere and the activation of the right hemisphere, for the exhibition of images in support printed guide. Whereas the logical mathematical structure of the preparation in Group 1 led the student to memorize a certain position of the photography, or to develop skills unrelated to the procedural contents of this subject, the techniques used in Group 2 allowed the development of observation of forms, textures and colors, and the spatial relations between the structures and elements inherent in the exploration of images in pathology. In conclusion, the discussion of images viewed from this neurobiological perspective and as a strategy of education, favors and stimulates significant learning of this morphological subject.

KEY WORDS: Education; Brain hemispheres; Image; Pathology.

\section{REFERENCIAS BIBLIOGRÁFICAS}

Ávila, R. E.; Samar, M. E.; Chiesa, P.; Camps, D.; Salica, J. P \& Yaryura, G. El uso de las nuevas tecnologías de información y comunicación (NTIC) para la enseñanza/ aprendizaje de Biología Celular, Histología y Embriología. Informedica Journal, 1(1), 2002.

Bruno, M.; Dorati, P. \& Casariego, Z. J. Encuesta de opinión: En pre-grado, 2003-2004 de Patología Oral y Estomatología. La Plata, Argentina. $A v$. Odontoestomatol., 22:187-94, 2006.

Dionisio de Cabalier, M. E. \& Chalub, D. M. El aprendizaje significativo de las ciencias morfológicas en medicina: experiencia y aportes para su enseñanza en clínica dermatológica. Int. J. Morphol., 27:565-9, 2009.

Edwards, B. Drawing on the right side of the brain. Madrid, Ed. Hermann Blume, 1988.

Edwards, B. Colors: A course in mastering the art of mixing colors. New York, Penguin Group Inc., 2004.
Fonseca, G. \& Fonseca, A. Técnicas de activación del Hemisferio Cerebral Derecho e Inteligencia Emocional como recursos aplicables a la enseñanza en Anatomía Patológica. Comunicación libre en el XI Congreso Argentino de Ciencias Morfológicas, I Congreso Internacional de Educación e Investigación en Ciencias Morfológicas y I Encuentro de Histotecnólogos, 14 al 16 de mayo, Córdoba, Argentina, 2008.

Froufe, M. \& Colom, R. Inteligencia racional vs. Inteligencia emocional. Universidad Autónoma de Madrid. Cuadernos de Educación. Madrid, Santillana, 1999.

García, H. F. Evaluación Práctica de la Anatomía Basada en la Teoría de las Inteligencias Múltiples de Gardner, Carrera de Odontología de la Universidad de Antofagasta, Chile. Int. J. Morphol., 24:83-8, 2006.

García, J. M. \& Rego, G. R. Paradigma de la enseñanza de Anatomía Patológica. Rev. Cubana Educ. Med. Sup., 12:54-61, 1998. 
García, J. M.; Stepien, A. \& Rego, G. R. Enseñanza Problémica de la Anatomía Patológica: Nuevas concepciones y enfoques sobre el aprendizje en adultos. X Congreso Virtual Hispanoamericano de Anatomía Patológica, 2009.

Gardner, H. Estructuras de la mente. La teoría de las inteligencias múltiples. Bogotá, Ed. Fondo de Cultura Económica Ltda., 2001.

Levie, H. \& Lentz, R. Effects of text illustrations: A review of research. Educ. Comm. Technol. J., 30:195-232, 1982.

Llorente, C. E. Imágenes en la enseñanza. Revista de Psicodidáctica, 9:119-35, 2000.

Merlo, F. T. La imagen como nuevo símbolo cultural. Agora Digital, 3:1-25, 2002.

Nazer, R.; Tellez, T.; Bassan, N. \& D’Ottavio, A. Enfoque innovador de la enseñanza-aprendizaje de histología y embriología. Educ. Med. Salud, 11:127-41, 1977.

Pellón, A; Mansilla, S. \& San Martín, C. Desafíos para la transposición didáctica y conocimiento didáctico del contenido en docentes de anatomía: obstáculos y proyecciones. Int. J. Morphol., 27:743-50, 2009.

Pellón, A. M.; Mansilla, S. J. \& San Martín, C. D. Importancia de la sabiduría didáctica práctica como fuente de conocimiento base para la enseñanza de la anatomía. Int. J. Morphol., 28:219-26, 2010.

Peresan, L. \& Adúriz, B. A. El arte en la histología. Publicación del II Congrés Internacional de Didactiques, 2010.

Portillo, A. La Asimetría Cerebral. Pausas y Ritmo en los procesos creativos. Icono, 14:6, 2005.
Rodríguez, P. I.; Iglesias, R. B.; Pomares, B. E.; Valenti, P. J. \& Dovale, B. A. Histología para estudiantes de Medicina. Un nuevo método que combina lo tradicional con técnicas computarizadas. VII Congreso Virtual Hispanoamericano de Anatomía Patológica y I Congreso de Preparaciones Virtuales por Internet, 2005.

Suazo, G. I.; Pretch, G. A.; Cantín, L. M.; Zavando, M. D. \& Sandoval, M. C. ¿Existe modelamiento profesional de los estilos de aprendizaje? Int. J. Morphol., 28:13-8, 2010.

Tamayo, H. M. \& González, G. F. Algunas dificultades en la enseñanza de la Histología animal. Rev. Electrón. Enseñ. Cienc., 2:177-200, 2003.

Val, B. J. \& Garijo, M. Hipócrates y su vigencia en la anatomía patológica actual. Rev. Esp. Patol., 36:95-100, 2003.

Dirección para correspondencia:

Gabriel Mario Fonseca

Cátedra de Anatomía Patológica B

Facultad de Odontología

Universidad Nacional de Córdoba

Haya de la Torre s/n, Ciudad Universitaria

Córdoba

ARGENTINA

Tel.: 54-0351-4687615

Email: gabriel_fonseca@argentina.com

Recibido : 19-07-2010

Aceptado: $14-09-2010$ 
